\title{
Combined Spinal-Epidural Anesthesia for Cesarean Section in a Pregnant Woman with a Ventriculoperitoneal Shunt
}

Volume 7 Issue 2 - 2017

\section{Letter to editor}

There is a number of case reports about anesthetic consideration in a pregnant woman with a VPS, both general and neuraxial anesthesia have been reported any complication directly associated with the anesthetic procedure..$^{1-5}$ To the best of our knowledge, a pregnant woman with a VPS was applied combined spinal-epidural anesthesia (CSEA) for cesarean section $(\mathrm{C} / \mathrm{S})$ has not been reported previously. Because of this, we aimed to present CSEA in a pregnant woman with a VPS for emergency C/S.

A 20-year-old pregnant woman (height; $152 \mathrm{~cm}$, and weight; $88 \mathrm{~kg}$ ), had been a VPS since she had 8 years old due to traumatic hydrocephalus, was scheduled emergency $\mathrm{C} / \mathrm{S}$ at 38 weeks gestation because of fetal distress. The patient had not neurological abnormalities. Physical examination and laboratory findings were normal. The patient had been fasting for approximately two hours. Because of this condition, CSEA was planned for $\mathrm{C} / \mathrm{S}$. The patient consent was obtained. The electrocardiography, non-invasive blood pressure, and pulse oximetry were established. The patient's baseline blood pressure, heart rate, and $\mathrm{SpO}_{2}$ were 124/67 mmHg, 92 per min, and 98\%, respectively. After intravenous access was obtained, $15 \mathrm{ml} / \mathrm{kg}$ of crystalloid infusion was started rapidly and $2 \mathrm{~g}$ of cefazolin was injected for antibiotic prophylaxis. $4 \mathrm{~L} / \mathrm{min}$ of oxygen was administered via a nasal cannula. With the patient in the sitting position, full aseptic precautions were taken. CSEA using $2 \mathrm{ml}$ of $0.5 \%$ isobaric bupivacaine intraspinally was applied in the midline at the L3-4 interspace. Five minutes later, the sensory block had reached the T4 dermatome and surgery was started. A $2770 \mathrm{~g}$ healthy girl baby was delivered. Any perioperative complications were not observed. When the sensory block was declined T10 dermatome at approximately 2 hours postoperatively, analgesia was obtained via epidural catheter with $15 \mathrm{ml}$ of solution, including $3 \mathrm{mg}$ morphine, $50 \mu \mathrm{g}$ fentanyl and $0.9 \% \mathrm{NaCl}$. The patient was observed for 48 hours with normal neurologic and vital status without pain and discharged home on postoperative day 2. When the patient was come back to Obstetrics department for control evaluation, any complaints associated with dural puncture headache or infection were not seen. ${ }^{5}$

In patients with a VPS, CSEA has increased the risk of infectious complications. ${ }^{1}$ If a CSEA is planned, strict aseptic techniques and antimicrobial prophylaxis should be complied with. ${ }^{1}$. Therefore, CSEA was applied in our patient under the antibiotic prophylaxis and strict aseptic condition. Our aim of using CSEA was rapidly reaching to appropriate level and quality of block with spinal block, and prolonged postoperative analgesia with epidural block. Besides, general anesthesia was avoided because of encountering with the risk of the difficult airway and gastric content aspiration in a fasting patient.

\author{
Onur PALABIYIK,' Ayse Nur KUMBASAR,' \\ Havva SAYHAN, ${ }^{2}$ Ayca TAS TUNA,2 Serkan \\ KUMBASAR ${ }^{3}$ \\ 'Department of Anesthesiology and Reanimation, Sakarya \\ University Training and Research Hospital,Turkey \\ ${ }^{2}$ Department of Anesthesiology and Reanimation, Sakarya \\ University, Faculty of Medicine, Turkey \\ ${ }^{3}$ Department of Obstetrics and Gynecology, Sakarya University \\ Training and Research Hospital, Turkey
}

Correspondence: Onur PALABIYIK, Sakarya University Training and Research Hospital, Department of Anesthesiology Intensive Care Unit, 54100 Sakarya, Turkey, Fax +90 264 275 |254, Email mdpalabiyikonur@yahoo.com

Received: January 09, 2017 | Published: January 18, 2017

Consequently, if strict sterile condition and antibiotic prophylaxis are provided, CSEA can be applied as an effective and safe anesthetic method for emergency $\mathrm{C} / \mathrm{S}$ in a patient with a VPS.

\section{Conflicts of interest}

There is no conflict of interest.

\section{Acknowledgements}

None.

\section{Funding}

None.

\section{References}

1. Littleford JA, Brockhurst NJ, Bernstein EP, et al. Obstetrical anesthesia for a parturient with a ventriculoperitoneal shunt and third ventriculostomy. Can J Anaesth. 1999;46(11):1057-1063.

2. Goulart AP, Moro ET, Rios Rde P, et al. Subarachnoid blockade for cesarean section in a patient with ventriculoperitoneal shunt: case report. Rev Bras Anestesiol. 2009;59(4):471-475.

3. Vybihal V, Gerychova R, Janku P, et al. [Pregnancy and delivery in patients with an implanted shunt for hydrocephalus]. Ceska Gynekol. 2014;79(4):309-313.

4. Nikolov A, Surchev Zh, Nalbanski B, et al. [Pregnancy and delivery in women with cerebrospinal fluid shunt due to hydrocephalus]. Akush Ginekol (Sofiia). 2008;47(2):3-10.

5. Schiza S, Stamatakis E, PanagopoulouA, et al. Management of pregnancy and delivery of a patient with malfunctioning ventriculoperitoneal shunt. J Obstet Gynaecol. 2012;32(1):6-9. 